\title{
Cardiac anomalies complicating congenital contractural arachnodactyly
}

Andrew J Macnab, Luigi D’Orsogna, David E C Cole, Paul E Baguley, Robert J Adderley, Michael W H Patterson

\begin{abstract}
A newborn boy with congenital contractural arachnodactyly (CCA) was found to have an atrial septal defect, ventricular septal defect, patent ductus arteriosus, and aortic arch anomalies. These resulted in congestive failure but subsequent progressive dilatation of both great arteries and development of aortic regurgitation were associated with eventual cardiorespiratory failure and death at 11.5 months. Others have noted that cardiac anomalies in CCA may be comparable with those of infantile Marfan's syndrome. Our case further extends the spectrum of cardiac abnormalities in CCA and substantiates that there is overlap with infantile Marfan's syndrome. This fact and our literature review suggest that early and complete cardiac assessment is necessary for appropriate management and evaluation of prognosis in any newborn infant with findings suggestive of either condition.
\end{abstract}

Beals and Hecht described the syndrome 'congenital contractural arachnodactyly' (CCA) as a dominantly inherited disorder of connective tissue characterised by multiple contractures, arachnodactyly, dolichostenomelia, scoliosis, and external ear anomalies. ${ }^{1}$ With increasing numbers of cases reported, the occasional association of cardiac anomalies with CCA has been repeatedly documented. ${ }^{2-7}$ Additional case reports have also emphasised the difficulty of distinguishing CCA from infantile Marfan's syndrome, ${ }^{8-11}$ which also carries a low but significantly increased frequency of cardiac anomalies other than those associated with progressive valvular and aortic disease. ${ }^{12}{ }^{13} \mathrm{We}$ report a well documented case of CCA in whom multiple congenital cardiac malformations were recognised in the newborn period, but progressive vascular changes more characteristic of infantile Marfan's syndrome eventually compromised airway patency and contributed to the child's early death. Literature review and our experience indicate that there is a subset of infants with major cardiac malformations whose presentation may be compatible with either infantile Marfan's syndrome or CCA, but is typical of neither. Our case underscores the need for early cardiac evaluation and regular echocardiographic monitoring in any infant presenting with features suggestive of either condition, as the presence of symptomatic heart disease in the first year of life is associated with a less favourable prognosis.

\section{Case report}

This infant boy was born at 37 weeks' gestation by elective caesarean section for breech presentation to a 25 year old woman who had had a previous caesarean section. There was no family history of significant congenital abnormalities and neither parent was noted to have marfanoid habitus or other features of Marfan's syndrome. Birth weight was $2300 \mathrm{~g}$ and Apgar scores were 7 and 9 at 1 and 5 minutes respectively. He was noted to be dysmorphic with retrognathia, crumpled ears, dolichostenomelia, arachnodactyly with flexion contractures of fingers, wrists, elbows, hips and knees, and kyphosis of the thoracic spine (fig 1 ).

His initial attempts to feed were unsuccessful, with frequent vomiting, and he was found on investigation to have duodenal atresia with malrotation. He also developed a hyperdynamic precordium with a systolic murmur, and an echocardiogram demonstrated an ostium primum atrial septal defect, a large inlet ventricular septal defect with discrete atrioiventricular valves, a patent ductus arteriosus, hypoplasia of the aortic arch, and preductal coarctation. The aortic root dimension measured $1.0 \mathrm{~cm}$ $\left(\right.$ normal $(2 \mathrm{SD})=1 \cdot 01 \mathrm{~cm}(0 \cdot 15) .^{14}$

Duodenoduodenostomy was performed on day 6 of life but postoperatively he developed intractable heart failure necessitating ligation of the patent ductus arteriosus, subclavian flap repair of the coarctation of the aorta, and pulmonary artery banding. His recovery was slow and he was eventually discharged at 3.5 months of age. Initial and subsequent ophthalmological examinations were normal with no evidence of lens dislocation, and cytogenetic analysis of chromosomes confirmed normal male karyotype (46, XY).

He next presented at 5 months of age with grey spells associated with stridor, cyanosis, bradycardia and apnoea, and subsequently required intubation and support with assisted ventilation. He had an active precordium and loud pulmonary flow murmur. Even though paralysed and ventilated, the grey spells continued, with bradycardia $(<60 / \mathrm{min})$ and falling oxygen saturation $(<80 \%)$. The chest radiograph demonstrated left lingular and right lower lobe collapse, and an echocardiogram showed an appreciably dilated aortic root with the aortic root dimension now $1 \cdot 7 \mathrm{~cm}$ (normal $(2 \mathrm{SD})=1 \cdot 21$ $\mathrm{cm}(0 \cdot 14))^{14}$ and similar appreciably dilated pulmonary arteries, both proximal and distal to the pulmonary artery band (fig 2). Flexible fibreoptic bronchoscopy demonstrated partial collapse of the distal half of the trachea to the 

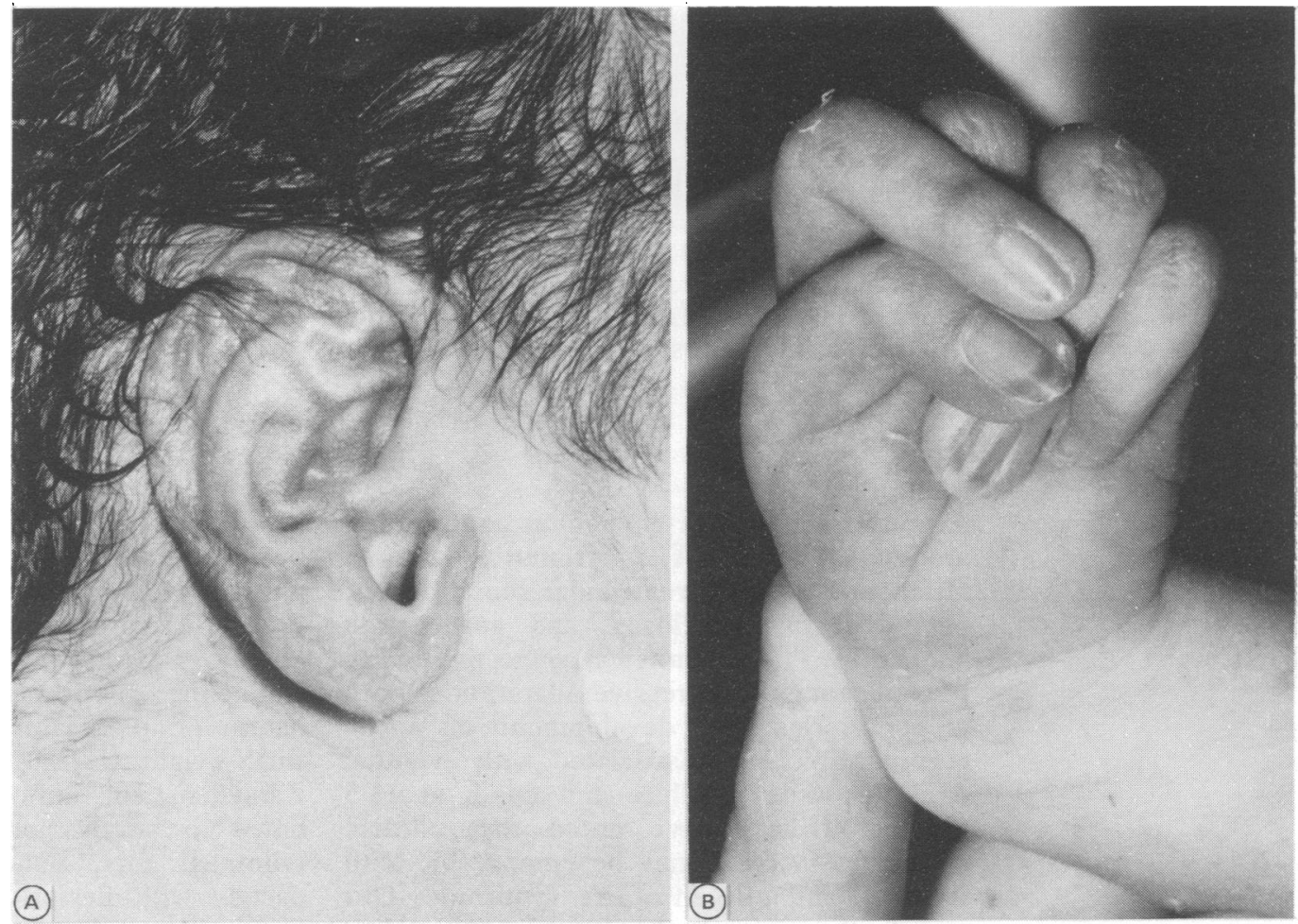

Figure 1 (A)Characteristic 'crumpled' ear deformity. (B) Arachnodactyly with flexion contractures of fingers and wrist.
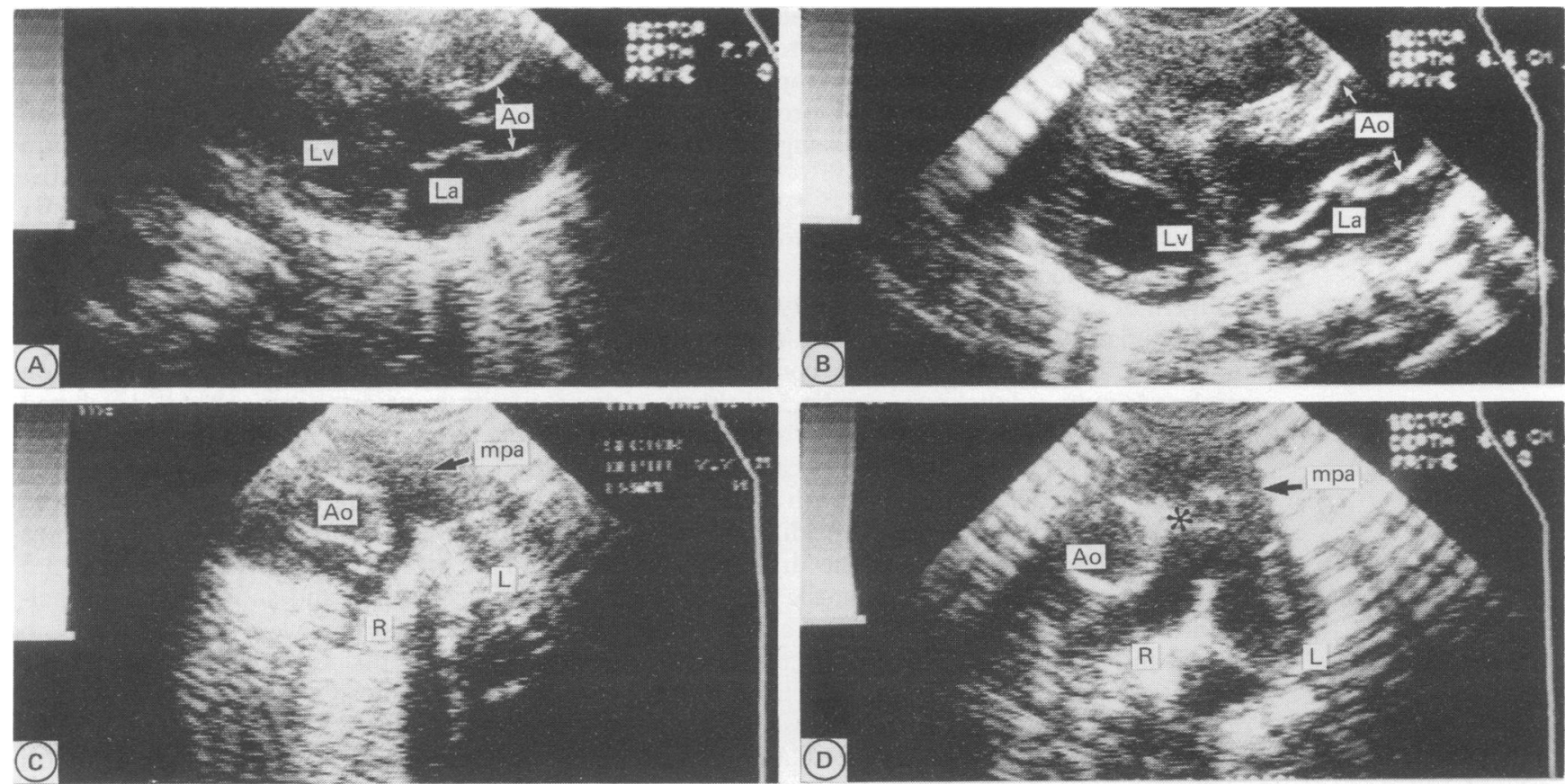

Figure 2 Echocardiogram. Parasternal long axis view at initial presentation $(A)$, and at 5 months $(B)$ illustrating appreciable dilatation of aortic root; white arrows define the inner margins of the aorta at the sinus of Valsalva. Parasternal short axis view at initial presentation $(C)$, and at 5 months $(D)$ illustrating appreciable dilatation of pulmonary arteries, proximal and distal to pulmonary artery band (*), compared with reference values. ${ }^{14}$ Ao, aorta; La, left atrium; $L v$, left ventricle; $L$, left pulmonary artery; $R$, right pulmonary artery; mpa, main pulmonary artery.

carina, either due to or compounded by extrinsic compression from the grossly dilated great arteries. He gradually responded to medical treatment and support and was discharged from hospital at 6 months of age.

Over the next five months, he thrived poorly but no hospital admissions were required. He was normotensive and his family doctor noted no visual abnormalities. At 11.5 months of age he developed bronchopneumonia with increasing respiratory distress. He was treated with antibiotics and supportive care but two days later had a further episode of airway obstruction with stridor and bradycardia from which he could not be resuscitated with intubation. No postmortem examination was performed.

\section{Discussion}

After the original description of the syndrome of CCA by Beals and Hecht in 1971, ${ }^{1}$ Lipson et al described a case of CCA with Klinefelter's 
syndrome and associated severe cardiovascular abnormalities. ${ }^{2}$ The cardiac anomalies were atrial septal defect, ventricular septal defect, patent ductus arteriosus, and interruption of the aortic arch, a combination of lesions which is strikingly similar to the initial cardiac malformations found in our case (see table). Lipson $e t$ al first emphasised the importance of distinguishing the pattern of cardiac involvement in CCA from infantile Marfan's syndrome; Macleod et al reiterated this concern because of the less favourable prognosis in the latter. ${ }^{15}$ In a review of the literature Ramos Arroyo et al (table) found nine of 61 cases of CCA $(15 \%)$ had cardiac malformations. ${ }^{3}$ Although six of the nine had mitral valve prolapse, no patients had dilatation of the aortic ring or aneurysm. Gruber et al reported a premature infant with CCA and severe heart failure due to mitral regurgitation, in whom appreciable dilatation of the aortic and pulmonary roots was detected at cardiac catheterisation. ${ }^{4}$ Subsequently, Bell and Wheller et al described an infant with CCA and severe dilatation of the roots of both great arteries with aortic insufficiency, ${ }^{5}$ and Huggon et al described an infant girl with CCA, iridodonesis, and mitral and tricuspid incompetence. ${ }^{6}$ All three infants died from cardiorespiratory failure. The occurrence of these severe cardiac lesions presenting in infancy, and the association of mitral valve prolapse with CCA, ${ }^{7}$ may make the distinction between CCA and infantile Marfan's syndrome more difficult to draw.

In a recent review, Geva et al summarised the cardiac abnormalities in 95 cases of infantile Marfan's syndrome ${ }^{13}$ (also tabulated in table). The most frequent lesion encountered was mitral valve prolapse $(96 \%)$ but it was not clinically significant. However, mitral and tricuspid incompetence were prominent $(84 \%$ and $31 \%$ of cases, respectively), and nearly all the fatalities were related to severe congestive failure secondary to atrioventricular valve regurgitation. Although aortic root dilatation was also frequently observed (94\%) and tended to progress, aortic valve regurgitation $(25 \%)$ was less common than in adult patients with Marfan's syndrome. Pulmonary artery dilatation (25\%) was also relatively frequent, in contrast to its rarity in adult patients.

Where cardiac disease is diagnosed early in life, cases tend to be more severe and there is a severely limited life expectancy, with most children dying in infancy. ${ }^{16}$ Echocardiography has increased the detection rate of mitral valve prolapse and progressive aortic root dilatation and there is convincing evidence that the mortality is roughly proportional to the degree of dilatation. ${ }^{17} 18$

Our report documents the case of an infant with CCA where the cardiac manifestations comprised a combination of the pathological lesions characteristic of both Marfan's syndrome and CCA. The initial presentation was with structural anomalies more commonly described for CCA, consisting of atrial septal defect, ventricular septal defect, persistent ductus arteriosus, and coarctation of the aorta. However, the patient subsequently developed marked dilatation of the great arteries similar to the cardiac manifestations of Marfan's syndrome, and tracheal compression by the dilated great vessels contributed to airway compromise.

Previous reports indicating the importance of distinguishing CCA and infantile Marfan's syndrome, because of a better prognosis in the former, should be interpreted cautiously. Serious cardiac malformations can occur in CCA, and when significant symptoms appear in the first year of life, may prove rapidly fatal. Contrary to other reports, we found that congenital heart malformations do occur in patients with CCA. Moreover, a similar spectrum of malformations is a recognised, albeit lower frequency, finding in infantile Marfan's syndrome. There are case reports which raise the

Features of infantile Marfan's syndrome, CCA, and variants

\begin{tabular}{|c|c|c|c|c|c|c|}
\hline & $\begin{array}{l}\text { Infantile } \\
\text { Marfan's } \\
\text { syndrome }{ }^{* 12} 13\end{array}$ & $\begin{array}{l}\text { Congenital } \\
\text { contractual } \\
\text { arachnodactyly } * 2>99\end{array}$ & $\begin{array}{l}\text { Gruber } \\
\text { et al }\end{array}$ & $\begin{array}{l}\text { Bell and } \\
\text { Wheller }^{5}\end{array}$ & $\begin{array}{l}\text { Huggon } \\
\text { et al }\end{array}$ & $\begin{array}{l}\text { Present } \\
\text { case }\end{array}$ \\
\hline $\begin{array}{l}\text { Diagnosis at birth } \\
\text { Family history } \\
\text { Contractures } \\
\text { Arachnodactyly } \\
\text { Ocular findings }\end{array}$ & $\begin{array}{l}6 / 40(15) \\
18 / 68(26) \\
6 / 9 \quad(67) \\
89 / 89(100) \ddagger \\
59 / 73(81)\end{array}$ & $\begin{array}{l}? \quad(100) \\
64 / 64(100) \\
55 / 64 \underset{(06)}{(86)}\end{array}$ & $\begin{array}{l}+ \\
\stackrel{+}{+}) \\
+ \\
+ \\
(-)\end{array}$ & $\begin{array}{l}+ \\
(-) \\
+ \\
+ \\
(-)\end{array}$ & $\begin{array}{l}+ \\
+ \\
+ \\
+ \\
+\end{array}$ & $\begin{array}{l}+ \\
+ \\
+ \\
+\end{array}$ \\
\hline Cardiovascular (all) & $(100)$ & $9 / 61 \quad(15)$ & + & + & + & + \\
\hline $\begin{array}{l}\text { Aorta } \\
\text { Dilatation } \\
\text { Regurgitation }\end{array}$ & $\begin{array}{ll}76 / 81 & (94) \\
15 / 60 & (25)\end{array}$ & $\begin{array}{l}0 \\
0\end{array}$ & $\stackrel{+}{(-)}$ & $\begin{array}{l}+ \\
+\end{array}$ & $\begin{array}{l}(-) \\
(-)\end{array}$ & $\begin{array}{l}+ \\
+\end{array}$ \\
\hline $\begin{array}{l}\text { Mitral valve } \\
\text { Prolapse } \\
\text { Regurgitation }\end{array}$ & $\begin{array}{ll}73 / 76 & (96) \\
64 / 76 & (84)\end{array}$ & $\begin{array}{l}6 \\
0\end{array}$ & $\begin{array}{l}+ \\
+\end{array}$ & $\begin{array}{l}+ \\
+\end{array}$ & $\begin{array}{l}+ \\
+\end{array}$ & $\begin{array}{l}(-) \\
(-)\end{array}$ \\
\hline $\begin{array}{l}\text { Tricuspid valve } \\
\text { Prolapse } \\
\text { Regurgitation }\end{array}$ & $\begin{array}{ll}27 / 51 & (53) \\
18 / 58 & (31)\end{array}$ & $\begin{array}{l}0 \\
0\end{array}$ & $\stackrel{+}{-}$ & $\begin{array}{l}+ \\
+\end{array}$ & + & $\stackrel{(-)}{+}$ \\
\hline $\begin{array}{l}\text { Pulmonary artery (dilatation } \\
\text { or regurgitation) } \\
\text { Major anomalies }\end{array}$ & $14 / 57 \quad(25)$ & 0 & $\stackrel{+}{(-)}$ & $(-)$ & $\begin{array}{l}(-) \\
(-)\end{array}$ & + \\
\hline $\begin{array}{l}\text { Atrial septal defect } \\
\text { Ventricular septal defect } \\
\text { Patent ductus arteriosus } \\
\text { Other } \\
\text { Aortic arch interruption }\end{array}$ & $\begin{array}{ll}3 / 45 & (7) \\
(-) & \\
(-) & \\
2 / 9 & (22) ף\end{array}$ & $\begin{array}{l}1 \\
2 \\
1 \\
1 \\
1\end{array}$ & $\begin{array}{l}(-) \\
(-) \\
(-) \\
(-)\end{array}$ & $\begin{array}{l}(-) \\
(-) \\
(-) \\
(-)\end{array}$ & $\begin{array}{l}(-) \\
(-) \\
(-) \\
(-)\end{array}$ & $\begin{array}{c}+ \\
+ \\
(+) \\
+\end{array}$ \\
\hline Aortic arch interruption & $(-)$ & 1 & $(-)$ & $(-)$ & $(-)$ & Duodenal \\
\hline Non-cardiac anomalies & $?$ & $\begin{array}{l}\text { Kleinfelter's syndrome, } \\
\text { TOF with duodenal atresia }\end{array}$ & & & & atresia \\
\hline
\end{tabular}

*Results are No/total No (\%); present, + ; absent, - ; absence inferred but not explicitly stated, (-)

$\neq$ Incidence based on assumption that arachnodactyly is part of the characteristic of musculoskeletal abnormalities.

TThe report of apparent coincidence of CCA and Marfan's syndrome with ocular findings is not included. ${ }^{10}$

The report of apparent coined at postmortem examination. ${ }^{13}$

TOF, tracheo-oesophageal fistula. 
question of what features decisively distinguish one condition from the other.

We would recommend careful echocardiographic examination and follow up of any child with congenital contractures and arachnodactyly in anticipation of significant cardiovascular complications appearing and progressing in a proportion of these children.

Neither our case nor the studies that precede it offer an obvious means of determining the extent of heterogeneity in the aetiology of either infantile Marfan's syndrome, congenital contractual arachnodactyly, or their intermediate variants. However, the localisation of Marfan's syndrome to chromosome 15 in families with adult Marfan's syndrome, ${ }^{19}$ and the mounting evidence for a central role of abnormal fibrillin protein in the pathogenesis of the connective tissue disorder, ${ }^{20}$ should prove extremely useful in clarifying the apparent distinctions between these related disorders.

1 Beals RK, Hecht F. Congenital contractual arachnodactyly: a heritable disorder of connective tissue. $\mathcal{F}$ Bone foint Surg [Am] 1971;53A:987-93.

2 Lipson EH, Viseskul C, Herrmann J. The clinical spectrum of congenital contractural arachnodactyly. Z Kinderheilk 1974;118:1-8.

3 Ramos Arroyo MA, Weaver DD, Beals RK. Congenital contractural arachnodactyly. Clin Genet 1985;17:570-81.

4 Gruber MA, Graham TP Jr, Engel E, Smith C. Marfan syndrome with contractural arachnodactyly and severe mitral regurgitation in a premature infant. $\mathcal{f}$ Pediatr 1978;93:80-20.
5 Bell RE, Wheller JJ. Cardiac defects in a patient with congenital contractural arachnodactyly. South Med J 1985; 78:742-3.

6 Huggon IC, Burke JP, Talbot JF. Contractural arachnodactyly with mitral regurgitation and iridodonesis. Arch Dis Child 1990;65:317-9.

7 Anderson RA, Koch A, Camerini-Otero RD. Cardiovascular findings in congenital contractural arachnodactyly. Am $\mathcal{J}$ Med Genet 1984;18:265-71.

8 Hecht F, Beals RK 'New syndrome' of congenital contractural arachnodactyly originally discovered by Marfan in 1896. Pediatrics 1972;49:574-9.

9 Currarino G, Friedman JM. A severe form of congenital contractural arachnodactyly in two newborn infants. $A m \mathfrak{F}$ contractural arachnodacty

10 Bass HN, Sparkes RS, Crandall BF, Marcy SM. Congenital contractural arachnodactyly, keratokonus, and probable Marfan syndrome in the same pedigree. $\mathcal{F}$ Pediatr 1981;98: 591-5.

11 Meinecke P. Marfan-like features and congenital contractural arachnodactyly. I Pediatr 1982;100:1006-7.

12 Phornphutkul C, Rosenthal A, Nadas AS. Cardiac manifestations of Marfan syndrome in infancy and childhood. Circulation 1973;45:587-95.

13 Geva T, Sanders SP, Diogenes MS, Rockenmacher S, Van Praagh R. Two-dimensional and Doppler echocardiographic and pathologic characteristics of the infantile Marfan syndrome. Am $\mathcal{Y}$ Cardiol 1990;65:1230-7.

14 Meyer RA. Pediatric echocardiography. Philadelphia: Lea and Febiger, 1977:292-3.

15 Macleod PM, Fraser DF. Congenital contractual arachnodactyly: a heritable disorder of connective tissue distinct dactyly: a heritable disorder of connective tissue distinct

16 Gross DM, Robinson LK, Smith LT, Glass N, Rosenberg H, Duvic M. Severe perinatal Marfan syndrome. Pediatrics Duvic $M$. Seve

17 Pyeritz R, Wappel M. Mitral valve dysfunction in the Marfan syndrome. Clinical and echocardiographic study of prevalence and natural history. Am $\mathcal{F}$ Med 1983;74:797-807.

18 Pyeritz R. Maternal and fetal complications of pregnancy in the Marfan syndrome. Am $\mathcal{F}$ Med 1981;71:784-90

19 Kainulainen K, Pulkkinen L, Savolainen A, Kaitila Peltonen L. Location on chromosome 15 of the gene defect causing Marfan syndrome. N Engl f Med 1990;323: 935-9.

20 Hollister DW, Godfrey M, Sakai LY, Pyeritz RE. Immunohistologic abnormalities of the microfibrillar-fiber system in the Marfan syndrome. N Engl f Med 1990;323:152-9. 